\title{
Comparison between high and low levels thoracic sympathectomy for the treatment of palmar and axillary primary hyperhidrosis: systematic review and meta-analysis
}

\section{Comparação da simpatectomia torácica realizada em níveis altos e baixos para o tratamento da hiperidrose primária palmar e axilar: revisão sistemática e metanálise}

Gilmar Felisberto Júnior, ACBC-SP; Cláudio José Rubira'; joão Paulo Sanches Berumudes²; Salum Bueno da-Silveira-Júnior².

A B S T R A C T

\begin{abstract}
Primary hyperhidrosis $(\mathrm{PH})$ is a condition that has a great impact on affected individuals' quality of life, regardless of its location. Its surgical treatment is done through thoracic sympathectomy performed by videothoracoscopy. Standardization of the technique includes section of the sympathetic trunk at different levels, according to the site of symptoms. The aim of this review is to evaluate the efficacy of thoracic sympathectomy through a systematic literature review comparing sympathectomy at different levels of the sympathetic chain.
\end{abstract}

Keywords: Hyperhidrosis. Sympathectomy. Thoracic Surgery, Video-Assisted. Meta-Analysis.

\section{INTRODUCTION}

$\mathrm{H}$ yperhidrosis is the excessive and uncontrollable sweating that goes beyond the thermoregulatory needs of the body. It occurs more often in the palm, axillary, plantar and face regions but can manifest in any region of the body. It is classified into primary, the most common, and secondary forms. The pathophysiology of primary hyperhidrosis $(\mathrm{PH})$ is not yet well established, constituting an idiopathic, chronic, usually focal, bilateral and symmetric alteration. Secondary hyperhidrosis has several etiologies, among which we can highlight fever, antidepressant drug use, neurological disorders, hyperthyroidism, obesity, stress, among others ${ }^{1,2}$.

$\mathrm{PH}$ affects men and women and manifests itself at various ages, being more common in adolescents and young adults. Approximately half of the patients have a positive family history ${ }^{3,4}$. The literature shows a highly variable prevalence for $\mathrm{PH}$ and its incidence varies according to cultural, climatic, and even conceptual, differences ${ }^{4}$. Strutton et al. ${ }^{5}$ found a prevalence of $2.8 \%$ in the North American population. In Brazil, there is little data on $\mathrm{PH}$ prevalence. A study conducted in the city of Botucatu-SP showed a prevalence of $0.93 \%$, predominantly in female patients ${ }^{6}$.

Its pathophysiology is not well understood. Morphological studies in the sweat glands of $\mathrm{PH}$ patients did not show changes in their number and histology. A complex dysfunction of the sympathetic autonomic nervous system, responsible for its innervation, may be related to its etiology². In an $\mathrm{PH}$ family history analysis, Yamashita et al. ${ }^{7}$ found a pattern of non-dominant autosomal transmission.

Although PH is not a life-threatening condition, it has a major impact on quality of life, interfering in the social, professional, psychic and emotional domains ${ }^{8}$. This is the main factor that causes PH patients to seek medical help.

Treatment may be clinical or surgical. Conservative alternatives are topical agents, anticholinergic drugs and beta-blockers, iontophoresis and the use of botulinum toxin ${ }^{9}$. Surgical treatment can be done through resection of sweat glands, curettage of the subcutaneous tissue and liposuction. However, the most accepted and best-reported

1 - University of Marília, Department of Thoracic Surgery, Marília, São Paulo State, Brazil. 2 - University of Marília, Medical School, Marília, São Paulo State, Brazil. 
treatment is videothoracoscopic sympathectomy, performed at different costal levels according to the location of symptoms ${ }^{4}$.

The purpose of this review was to compare the efficacy of videothoracoscopic sympathectomy performed at different levels of the sympathetic chain in patients with $\mathrm{PH}$.

\section{METHODS}

We performed a search for the interest studies in the following databases: Pubmed, Embase, Cochrane, Lilacs and Clinical trials. The descriptors used to construct the search strategy were: primary hyperhidrosis, assisted video thoracic sympathectomy or videothoracoscopy. In order to increase the search sensitivity, we adapted the strategy to each base and, in addition, we used meSH terms for Pubmed, Cochrane and Clinical Trials databases, Emtree terms for Embase, and DEC terms for Lilacs. Two reviewers independently selected the studies. The eligibility criteria used were: prospective, randomized or quasirandomized studies; Patients with $\mathrm{PH}$; Presence of two groups comparing different thoracic levels for the sympathectomy, the highest or broadest level being considered the standard procedure. The primary outcome was symptom remission, and the secondary, the incidence of compensatory sweating.

We analyzed the titles and abstracts of the works found to identify the articles that obeyed the

\section{Risk Ratio}

\section{M-H, Fixed, 95\% Cl}

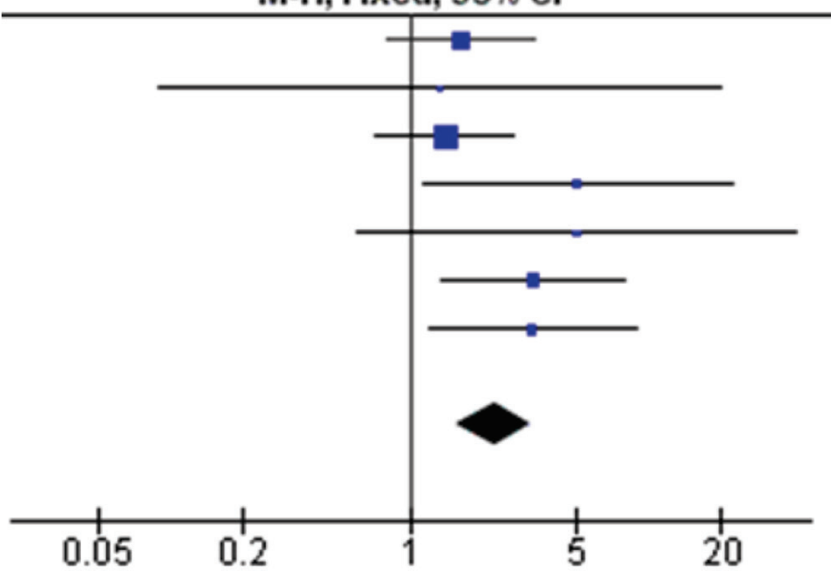

inclusion criteria. A third reviewer was available to resolve possible disagreements. We obtained the selected articles in their respective entireties and analyzed their bibliographic references in the search for other possibly eligible studies. Two reviewers independently extracted the data in a standard form. We evaluated the quality of the studies by verifying, for each one, the criteria of randomization, incomplete presence of outcome data, selective reporting of outcomes, presence of blindness for participants and investigators, and presence of other biases.

Since the primary goal of hyperhidrosis treatment is to improve patients' quality of life, for the primary outcome we included the data of patients who had complete remission of symptoms or who reported great satisfaction with surgery. We assessed compensatory sweating in a similar way, taking into account the data from all patients in whom the event significantly compromised quality of life.

For the meta-analysis, we considered the outcomes as dichotomous variables and the measure of effect was the relative risk, with fixed effect and confidence interval $(\mathrm{Cl})$ of $95 \%$. We assessed the inconsistencies between studies through the heterogeneity test (I2), considering values above $70 \%$ as important. We summarized the results in the forest plot, with the combined estimate of the effect marked as a diamond at the bottom of the chart. Subgroup analyzes and sensitivity analyzes were planned to explain the possible causes of high

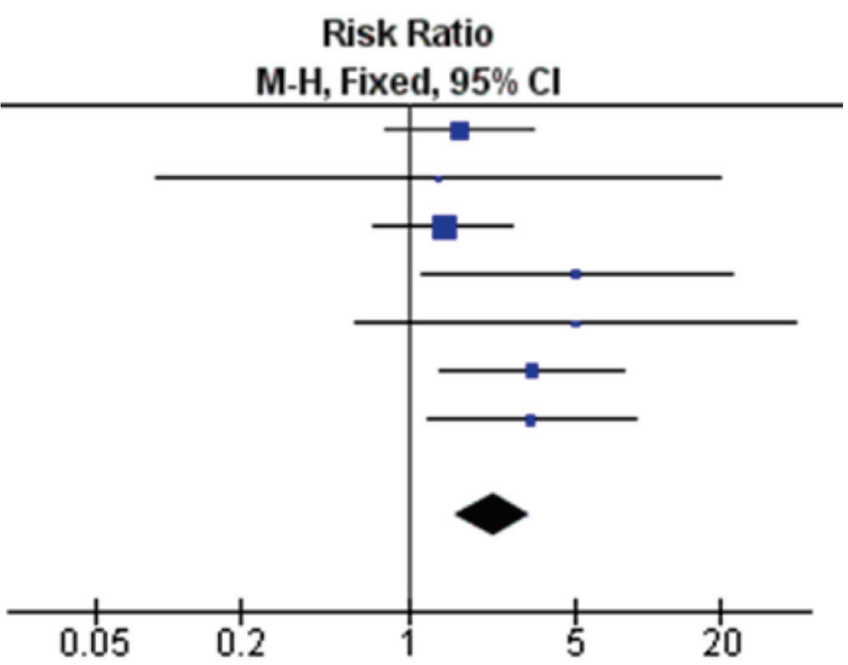

Figure 2. Compensatory Sweating for palmar PH.

Figure 1. Symptom control for palmar PH. 
Table 1. Studies included in the review.

\begin{tabular}{lcccc}
\multicolumn{1}{c}{ Author/Year } & High levels & Low levels & Levels compared & Location of symptoms \\
\hline Baumgartner, 2007 & 61 & 60 & T2/T3 & Palmar \\
Ishy, 2010 & 20 & 20 & T3/T4 & Palmar \\
Li, 2008 & 115 & 117 & T2-4/T3 & Palmar \\
Liu, 2009 & 68 & 73 & T3/T4 & Axillary \\
Munia, 2007 & 32 & 30 & T3-4/T4 & Axillary \\
Munia, 2008 & 31 & 33 & T3-4/T4 & Palmar \\
Vicidomi, 2011 & 50 & 50 & T2-4/T3 & Palmar \\
Yang, 2009 & 78 & 85 & T3/T4 & Palmar \\
Yasbek, 2009 & 30 & 30 & T2/T3 & Axillary \\
Yuncu, 2013 & 17 & 43 & T3-4/T4 & \\
\hline
\end{tabular}

heterogeneity. We performed statistical analysis with the software Review Manager from Cochrane Collaboration, version 5.3.5, available free of charge for download.

\section{RESULTS}

The search conducted in April 2015 returned 1086 articles in Pubmed, 60 articles in Lilacs, 92 articles in Embase, two articles in Cochrane Central Station and five articles in Clinical Trials. After the removal of duplicate sources and analysis of titles and abstracts, we selected 33 articles for integral evaluation. From this amount, ten articles brought the inclusion criteria for this review. We performed a new search in August 2015, and included no more study in the review. The works analyzed data from 857 patients with palmar hyperhidrosis and 186 patients with axillary hyperhidrosis, totaling 1,043 individuals. There was a slight predominance of female patients and the mean age ranged from 21.2 to 29.7 years. Table 1 summarizes the main characteristics of each study.

As for the levels of surgery, for palmar hyperhidrosis, Yazbek et al. ${ }^{10}$ and Baumgartner et al. ${ }^{11}$ compared levels T2 and T3. Vicidomini et al. ${ }^{12}$ and Li et al. ${ }^{13}$ compared levels T2-4 and T3, and Liu et al. ${ }^{14}$, Yang et al. ${ }^{15}$ and Ishy et al. ${ }^{16}$ compared levels T3 and T4. To perform the meta-analysis of the primary outcome, we considered the larger resections taking into account the first sectioned level. For palmar PH, was carried out the meta-analysis without two articles that were not included because they brought the results as averages.

The analysis performed with the four remaining articles included data from 413 patients. The relative risk (RR) found was $0.86(95 \% \mathrm{Cl} 0.79$ 0.94) favoring the group submitted to the lowest resection. However, the heterogeneity (12) found was $83 \%(p=0.0007)$. In order to explain this high heterogeneity, we performed a sensitivity analysis with the withdrawal of one study. Thus, we found an 12 of $0 \%(p=0.91)$ and RR of 0.95 (95\% Cl 0.88-1.03) without significant difference between the two types of resection (Table 2, Figure 1). For the secondary outcome (Table 2, Figure 2), compensatory sweating, the meta-analysis showed a greater risk of this event for the group submitted to the higher or larger resections, with RR of 2.26 (95\% Cl 1.57-3.25), and 12 of $0 \%(p=0.46)$

As for the axillary symptoms, Munia et al. ${ }^{17,18}$ compared levels T3-4 and T4 alone, and Yunku et al. ${ }^{19}$ compared levels T3-4 with T3 alone. We made the meta-analysis for the primary outcome without including one study that reported the results as means. The results showed a RR of 0.83 (95\% Cl 0.70-0.99) and $1241 \%(p=0.19)$, favoring the group submitted to the lower section (Table 2 , 
Figure 3). The chance of presenting compensatory sweating was higher in the group submitted to the higher section, with RR of 2.03 (95\% Cl 1.49-2.76), but with 12 of $94 \%(p<0.0001)$. We then performed a sensitivity analysis by excluding one study in which all patients in the higher resection group had compensatory sweating. Thus, the meta-analysis showed a RR of 7.25 (95\% Cl 2.30-22.84) and 12 of
$0 \%(p=0.51)$, favoring the group submitted to the lowest resection (Table 2, Figure 4).

\section{DISCUSSION}

$\mathrm{PH}$ is a condition that, despite benignity, severely compromises the quality of life of affected individuals. Symptoms may begin in childhood and

Table 2. Palma HP.

\begin{tabular}{|c|c|c|c|c|c|c|}
\hline \multirow[b]{2}{*}{ Study or Subgroup } & \multicolumn{2}{|c|}{ Higher level } & \multicolumn{2}{|c|}{ Lower level } & \multirow[b]{2}{*}{ Weight } & \multirow{2}{*}{$\begin{array}{c}\text { Risk Ratio } \\
\text { M-H. Fixed 95\% Cl}\end{array}$} \\
\hline & Events & Total & Events & Total & & \\
\hline \multicolumn{7}{|c|}{ * Symptom control for palmar PH. } \\
\hline Baumgartner, 2001 & 37 & 41 & 38 & 40 & $21.4 \%$ & $0.95[0.84,1.07]$ \\
\hline Li, 2008 & 89 & 115 & 96 & 117 & $53.0 \%$ & $0.94[0.83,1.07]$ \\
\hline Liu, 2009 & 15 & 62 & 40 & 69 & $0.0 \%$ & $0.42[0.26 .0 .68]$ \\
\hline Vicidomini, 2011 & 45 & 50 & 46 & 50 & $25.6 \%$ & $0.98[0.86,1.11]$ \\
\hline Total $(95 \% \mathrm{Cl})$ & & 206 & & 207 & $100.0 \%$ & $0.95[0.88,1.03]$ \\
\hline Total events & 171 & & 180 & & & \\
\hline \multicolumn{7}{|c|}{ ** Compensatory Sweating for palmar PH. } \\
\hline Baumgartner, 2001 & 16 & 50 & 9 & 46 & $26.2 \%$ & $1.64[0.80,3.33]$ \\
\hline Ishi, 2010 & 1 & 15 & 1 & 20 & $2.4 \%$ & $1.33[0.09,19.64]$ \\
\hline Li, 2008 & 18 & 115 & 13 & 117 & $36.0 \%$ & $1.41[0.72,2.74]$ \\
\hline Liu, 2009 & 9 & 62 & 2 & 69 & $5.3 \%$ & $5.01[1.12,22.29]$ \\
\hline Vicidomini, 2011 & 5 & 50 & 1 & 50 & $2.8 \%$ & $5.00[0.61,41.28]$ \\
\hline Yang, 2009 & 18 & 78 & 6 & 85 & $16.1 \%$ & $3.27[1.37,7.81]$ \\
\hline Yasbek, 2009 & 13 & 30 & 4 & 30 & $11.2 \%$ & $3.25[1.20,8,83]$ \\
\hline Total $(95 \% \mathrm{Cl})$ & & 400 & & & $100.0 \%$ & $2.26[1.57,3.25]$ \\
\hline Total events & 80 & & 36 & 417 & & \\
\hline \multicolumn{7}{|c|}{ *** Symptom Control for axillary PH. } \\
\hline Munia, 2007 & 28 & 32 & 29 & 30 & $58.2 \%$ & $0.91[0.78,1.05]$ \\
\hline Yuncu, 2013 & 11 & 17 & 38 & 43 & $41.8 \%$ & $0.73[0.51,1.06]$ \\
\hline Total $(95 \% \mathrm{Cl})$ & & 49 & & 73 & $100.0 \%$ & $0.83[0.70,0.99]$ \\
\hline Total events & 39 & & 67 & & & \\
\hline \multicolumn{7}{|c|}{$* * * *$ Compensatory sweating for axillary $\mathrm{PH}$. } \\
\hline Munia, 2007 & 11 & 32 & 2 & 30 & $68.1 \%$ & $5.16[1.24,21.37]$ \\
\hline Munia, 2008 & 11 & 31 & 1 & 33 & $31.9 \%$ & $11.71[1.60,85.45]$ \\
\hline Yuncu, 2013 & 17 & 17 & 34 & 43 & $0.0 \%$ & $1.24[1.04,1.48]$ \\
\hline Total $(95 \% \mathrm{Cl})$ & & 63 & & 63 & $100.0 \%$ & $7.25[2.30,22.84]$ \\
\hline Total events & 22 & & 3 & & & \\
\hline
\end{tabular}




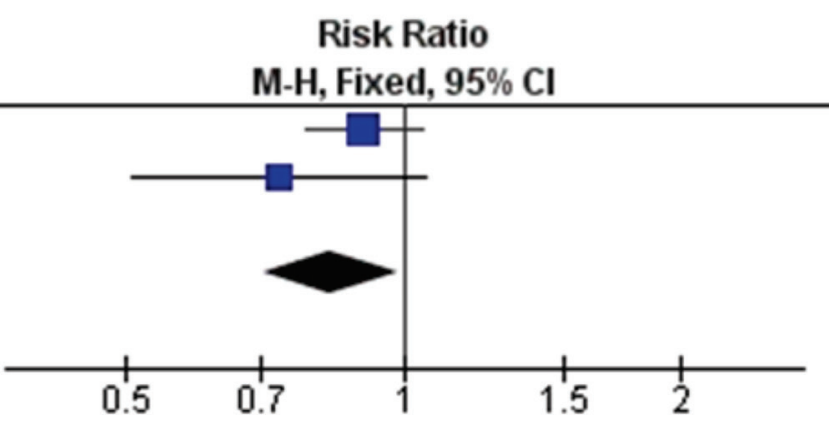

Figure 3. Symptom Control for axillary PH.

tend to worsen during adolescence ${ }^{4}$. Responses with clinical treatments vary widely, but generally do not show satisfactory results. In this context, videothoracoscopic sympathectomy presents as an effective alternative, with low complications rates and satisfactory results ${ }^{4,8}$.

The first sympathectomy reported was made in 1889. Kux, in 1940, performed the first thoracoscopic sympathectomy ${ }^{20}$. Sincethen, sympathectomy has gained strength in the treatment of $\mathrm{PH}$ and has become the standard procedure for these cases. Several techniques for the interruption of the sympathetic chain have been described and the literature does not yet indicate the superiority of any of them ${ }^{4}$. Despite the large number of published studies, a point of great interest and still a source of divergence is the costal level of sympathetic trunk section. In the literature there are retrospective series that did not show significant differences between the high and low surgical approaches ${ }^{4}$. This systematic review of prospective and randomized studies evaluated symptom control in 413 patients with palmar $\mathrm{PH}$ and the incidence of compensatory sweating in 817 . For axillary $\mathrm{PH}$, the number of patients was lower, 122 for the primary outcome and 126 for the secondary. Despite this, there was no significant heterogeneity in the analyzes.

The studies recorded no deaths and, although the rates of complications were poorly reported, they were low. This is due to the standardization of the surgical technique and the profile of the operated patients, who are usually young and without comorbidities.

For palmar hyperhidrosis, the meta-analysis did not show significant differences between the

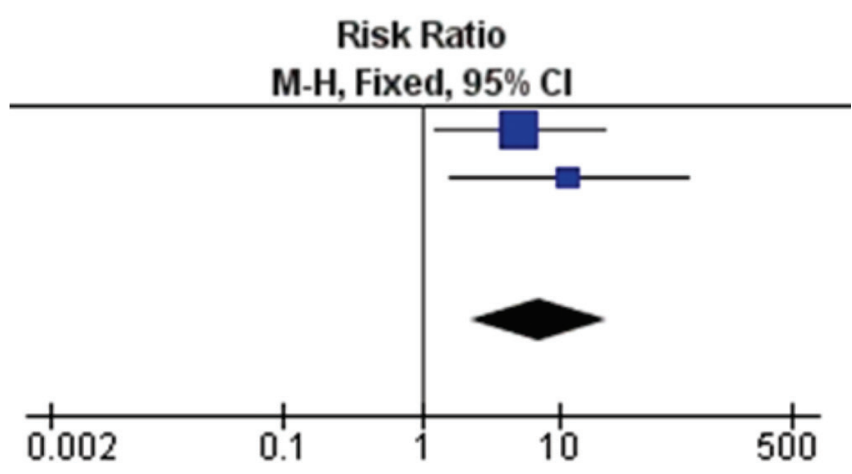

Figure 4. Compensatory Sweating for axillary PH.

groups for the primary outcome. In the upper sections, $83 \%$ of the patients had remission of symptoms or significant improvement. For the intervention group, $86 \%$ of the patients presented the same results. For compensatory sweating, the difference between the groups was very clear, with a risk 2.07 times higher of the event occurring in the higher or broader resections. In the last consensus based on the literature organized by The Society of Thoracic Surgeons (STS) ${ }^{4}$, the indication lower levels section for axillary hyperhidrosis showed low rates of compensatory sweating, but also lower rates of symptoms remission. This difference in outcome probably occurred because the STS review included prospective, randomized, non-randomized, and even retrospective studies.

For axillary, axillary-palmar, or axillary-palmarplantar PH cases, the STS revision showed better results with surgery performed at lower costal levels. This review found similar results, and with statistical significance. For the primary outcome, rates in the high and low section groups were, respectively, $79 \%$ and $91 \%$. The risk of developing compensatory sweating was 7.25 times higher in the control group. Data from the literature show important rates of compensatory sweating, varying from 14 to $90 \%$. Obviously, there are many associated factors that must be considered, since a good part of these data derive from retrospective series with different indications and surgical techniques. In this review, in the control group, approximately 34\% of the patients reported compensatory sweating, whereas this number was $5 \%$ for lower sections.

Despite the small number of studies available, the meta-analysis has shown that for palmar $\mathrm{PH}$, lower 
sections are as effective as high ones for symptoms control or remission, but display lower rates of compensatory sweating. As for axillary $\mathrm{PH}$, procedures done at lower levels are more effective and have lower rates of compensatory sweating. Thus, low resections, based on data from the current literature, are the best options for the treatment of axillary and palmar $\mathrm{PH}$, with good satisfaction rates and improvement of patients' quality of life. Further prospective and randomized studies are needed to elucidate which groups of patients benefit most from surgical treatment and which techniques may be most effective.

\title{
R E S U M O
}

\begin{abstract}
A hiperidrose primária (HP) é uma condição que, independentemente de sua localização, apresenta grande impacto na qualidade de vida dos indivíduos acometidos. Seu tratamento cirúrgico é feito através da simpatectomia torácica realizada por videotoracoscopia. A padronização da técnica inclui a secção do tronco simpático em diferentes níveis, de acordo com o local dos sintomas. O objetivo desta revisão é avaliar a eficácia da simpatectomia torácica por meio de uma revisão sistemática da literatura, comparando a simpatectomia em diferentes níveis da cadeia simpática.
\end{abstract}

Descritores: Hiperidrose. Simpatectomia. Cirurgia Torácica Videoassistida. Metanálise.

\section{REFERENCES}

1. Santana-Rodríguez N, Clavo B, Calatayud-Gastardi J, García-Castellano JM, Ponce-González MA, Olmo-Quintana $V$, et al. Severe compensatory hyperhidrosis following thoracic sympathectomy successfully treated with low doses of botulinum toxin A. J Dermatolog Treat. 2012;23(6):457-60.

2. de Oliveira FR, Moura Jr NB, de Campos JR, Wolosker N, Parra ER, Capellozi VL, et al. Ann Vasc Surg. 2014;28(4):1023-9.

3. Wolosker N, Krutman M, Kauffman P, Paula RP, Campos JR, Puech-Leão P. Effectiveness of oxybutynin for treatment of hyperhidrosis in overweigth and obese patients. Rev Assoc Med Bras. 2013;59(2):143-7.

4. Cerfolio RJ, de Campo JR, Bryant AS, Connery $C P$, Miller DL, DeCamp MM, et al. The Society of Thoracic Surgeons expert consensus for the surgical treatment of hyperhidrosis. Ann Thorac Surg. 2011;91(5):1642-8.

5. Strutton DR, Kowalski JW, Glaser DA, Stang PE. US prevalence of hyperhidrosis and impact on individuals with axillary hyperhidrosis: results form a national survey. J Am Acad Dermatol. 2004;51(2):241-8.

6. Hasimoto EN. Hiperidrose na cidade de Botucatu: prevalência, orientação, tratamento e qualidade de vida [dissertação]. Botucatu (SP): Universidade Estadual Paulista Júlio de Mesquita Filho; 2012.

7. Yamashita N, Tamada Y, Kawada M, Mizutani K,
Watanabe D, Matsumoto Y. Analysis of family history of palmoplantar hyperhidrosis in Japan. J Dermatol. 2009;36(12):628-31.

8. Baroncello JB, Baroncello LRZ, Schneider EGF, Martins GG. Avaliação da qualidade de vida antes e após simpatectomia por videotoracoscopia para tratamento da hiperidrose primária. Rev Col Bras Cir. 2014;41(5):325-30.

9. Teivelis MP, Wolosker N, Krutman M, Milanez de Campos JR, Kauffman P, Puech-Leão P. Compensatory hyperhidrosis: results of pharmacologic treatment with oxybutynin. Ann Thorac Surg. 2014;98(5):1797-802.

10. Yazbek G, Wolosker N, Kauffman P, Campos $J R$, Puech-Leão $P$, Jatene FB. Twenty months of evolution following sympathectomy on patients with palmar hyperidrhosis: sympathectomy at the T3 level is better than at the T2 level. Clinics. 2009;64(8):743-9.

11. Baumgartner FJ, Reyes M, Sarkisyan GG, Iglesias A, Reyes E. Thoracoscopy symphathicotomy for disabling palmar hyperhidrosis: a prospective randomized comparison between two levels. Ann Thorac Surg. 2011;92(6):2015-9.

12. Vicidomini G, Fiorelli A, Milione R, Napolitano F, Santini M. Long-term outcomes after video-assisted thoracic sympathectomy for palmar hyperhidrosis: a prospective study comparing T3 and T2T4 ablation [abstract]. Interact Cardiovasc Thorac Surg. 2011;13 Suppl 1:S48. 
13. LiX, Tu YR, Lin M, Lai FC, Chen JF, Dai ZJ. Endoscopic thoracic symathectomy for palmar hyperhidrosis: a randomized control trial comparing $\mathrm{T} 3$ and T2-4 ablation. Ann Thorac Surg. 2008;85(5):1747-51.

14. Liu Y, Yang J, Liu J, Yang F, Jiang G, Li J, et al. Surgical treatment of primary palmar hyperhidrosis: a prospective randomized study comparing T3 and T4 sympathicotomy. Eur J Cardiothorac Surg. 2009;35(3):398-402.

15. Yang J, Tan JJ, Ye GL, Gu WQ, Wang J, Liu YG. T3/T4 thoracic sympathictomy and compensatory sweating in treatment of palmar hyperhidrosis. Chin Med J (Engl). 2007;120(18):1574-7.

16. Ishy A, de Campos JR, Wolosker N, Kauffman $P$, Tedde ML, Chiavoni CR, et al. Objective evaluation of patients with palmar hyperhidrosis submitted to two levels of sympathectomy: T3 and T4. Interact Cardiovasc Thorac Surg. 2011;12(4):545-8.

17. Munia MA, Wolosker $N$, Kauffman $P$, de Campos JR, Puech-Leão P. A randomized trial of T3-T4 versus T4 sympathectomy for isolated axillary hyperhidrosis. J Vasc Surg. 2007;45(1):130-3.
18. Munia MA, Wolosker N, Kauffman P, de Campos JR, Puech-Leão P. Sustained benefit lasting one year from T4 instead of T3-T4 sympathectomy for isolated axillary hyperhidrosis. Clinics. 2008;63(6):771-4.

19. Yuncu G, Turk F, Ozturk G, Atinkaya C. Comparison of only T3 and T3-T4 sympathectomy for axillary hyperhidrosis regarding treatment effect and compensatory sweating. Interact Cardiovasc Thorac Surg. 2013;17(2):263-7.

20. Krasna MJ. The role of surgical treatment of hyperhidrosis. Mayo Clin Proc. 2011;86(8):717-8.

Received in: 08/07/2016

Accepted for publication: 26/09/2016

Conflict of interest: none.

Source of funding: none.

\section{Mailing address:}

Gilmar Felisberto Junior

E-mail: crtorax@gmail.com / gfj38@uol.com.br 